\title{
Annular pancreas concurrent with pancreaticobiliary maljunction presented with symptoms until adult age: case report with comparative data on pediatric cases
}

\author{
Long Cheng ${ }^{1,2}$, Fuzhou Tian ${ }^{1 *}$, Tiejun Zhao ${ }^{1}$, Yong Pang ${ }^{1}$, Zhulin Luo ${ }^{1}$ and Jiandong Ren ${ }^{1}$
}

\begin{abstract}
Background: Annular pancreas (AP) concurrent with pancreaticobiliary maljunction (PBMJ), an unusual coexisted congenital anomaly, often presented symptoms and subjected surgical treatment at the early age of life. We reported the first adult case of concurrent AP with PBMJ presented with symptoms until his twenties, and performed a literature review to analyze the clinicopathological features of such cases comparing with its pediatric counterpart.

Case presentation: The main clinical features of this case were abdominal pain and increased levels of plasma amylase as well as liver function test. A complete type of annular pancreas with duodenal stenosis was found, and dilated common bile duct with high confluence of pancreaticobiliary ducts was also observed. Meanwhile, extremely high levels of bile amylase were detected both in common bile duct and gallbladder. The patient received duodenojejunostomy (side-to-side anastomosis) as well as choledochojejunostomy (Roux-en-Y anastomosis), adnd was discharged in a good condition.

Conclusion: AP concurrent with PBMJ usually presents as duodenal obstruction in infancy, while manifests as pancreatitis in adulthood. Careful long-term follow-up is required for children with AP considering its association with PBMJ which would induce various intractable pathologic conditions in the biliary tract and pancreas.
\end{abstract}

Keywords: Annular pancreas, Pancreaticobiliary maljunction, Pancreatitis

\section{Background}

Annular pancreas (AP) is a rare congenital anomaly that is frequently associated with duodenal atresia (DA) or duodenal stenosis (DS) [1]. Pancreaticobiliary maljunction (PBMJ) is another congenital anomaly defined as an anatomical maljunction of the pancreatic duct and the biliary duct outside of the duodenal wall beyond the influence of the sphincter of Oddi, usually forming a markedly long common channel [2]. PBMJ and AP are embryologically closely related entities [3]; however, there have been only a limited number of case reports. To the best of our knowledge, only 11 pediatric cases

\footnotetext{
*Correspondence: tfz3006101@163.com

1 Department of General Surgery, General Hospital of Chengdu Military

Command, Chengdu, Sichuan Province, People's Republic of China

Full list of author information is available at the end of the article
}

have been documented in detail, but no adult case has been reported previously in English literature [4-13]. The authors report the first adult case with a literature review to analyze the clinicopathological features of such cases, and emphasize that the unusual coexistence of the two anomalies should be pay much attention in the diagnosis and treatment of recurrent pancreatitis and in the prevention of cancers originating from bile duct and gallbladder.

\section{Case presentation}

The patient, a 26-year-old man, presented to our department with abdominal pain. He was born at 40 weeks' gestational age with a birth weight of 3,010 g. Since his 3 years of age, the patient presented with relatively greater appetite compared with corresponding age cohorts and

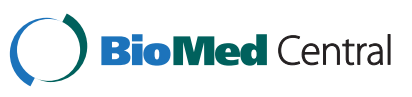


wiggly epigastric mass which would disappear two hours after meal. He remained free from vomiting and acute abdomen until the first episode of abdominal pain at the age of 23 years. Since then, he underwent totally 3 episodes of acute abdomen, and was diagnosed with acute pancreatitis.

On presentation, physical examination revealed tender epigastrium without palpable mass and jaundice. Laboratory data showed abnormal liver and pancreatic function tests with elevated serum levels of aspartate aminotransferase ( $85 \mathrm{U} / \mathrm{L}$; normal range, $0-40 \mathrm{U} / \mathrm{L})$, alanine aminotransferase $(72 \mathrm{U} / \mathrm{L}$; normal range, $0-40 \mathrm{U} / \mathrm{L})$, total bilirubin (32.7 $\mu \mathrm{mol} / \mathrm{L}$; normal range, $0-19.5 \mu \mathrm{mol} / \mathrm{L})$, amylase (541 $\mathrm{U} / \mathrm{L}$; normal range, 25-125 U/L) and lipase (279 U/L; normal range, $<190 \mathrm{U} / \mathrm{L}$ ). Abdominal sonography revealed a dilated common bile duct. Computerized tomography additionally showed the dilation of proximal duodenum with stenosis at the distal end of descending duodenum. Magnetic resonance imaging and cholangiopancreatography revealed fusiform dilatation of the common bile duct with high confluence of pancreaticobiliary ducts with a common channel measured $24 \mathrm{~mm}$ in length (Figure 1A, B). Endoscopy showed an enlarged pylorus and excessively ectatic duodenal cavity, but endoscopic retrograde cholangiopancreatography was not successful due to duodenal stenosis at the descending part (Figure 2). A tentative diagnosis of acute pancreatitis associated with pancreaticobiliary maljunction and annular pancreas was made.

During laparotomy, a complete type of annular pancreas and a fusiform-type dilatation of common bile duct were confirmed. Air charging demonstrated an enlarged pylorus and excessively ectatic duodenal bulb with duodenal stenosis at the distal end of descending part (Figure 3). Pancreatic amylase was at extremely high levels in the bile within the common bile duct and gallbladder sampled immediately after laparotomy $(5592.8 \mathrm{U} / \mathrm{L}$ and 85694.0 U/L, respectively). Transection of the dilated common bile duct and choledochojejunostomy were performed.

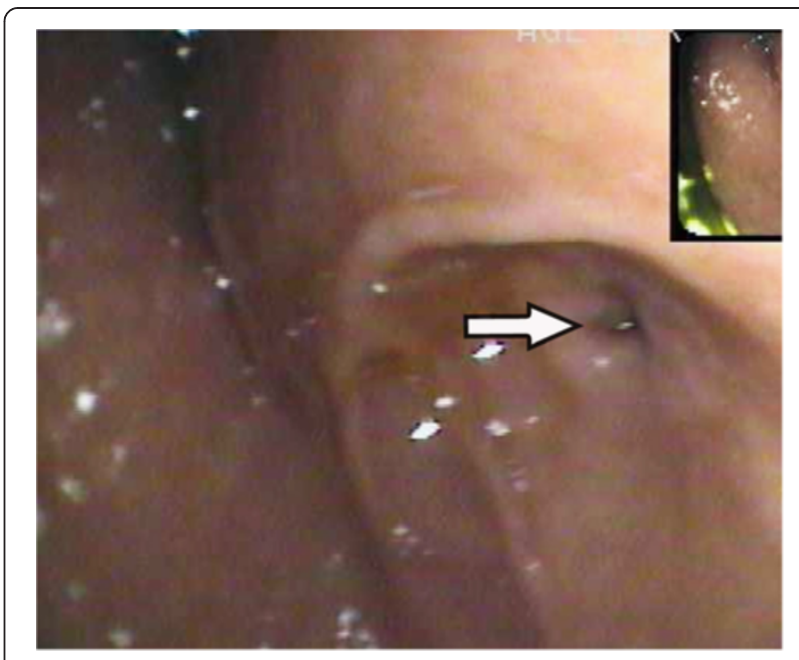

Figure 2 Endoscopic appearance. Endoscopy showed an enlarged pylorus and excessively ectatic duodenal cavity. Endoscopic retrograde cholangiopancreatography (ERCP) was not successful in confirming the pancreaticobiliary maljunction due to duodenal stenosis (arrow).

Patient also underwent duodenojejunostomy for correction of duodenal stenosis associated with annular pancreas.

The postoperative course was uneventful. The patient was discharged on the 21th postoperative day on full oral feeding and without abdominal pain. The patient has been free from abdominal pain with normal serum amylase levels in the follow-up period of 12 months postoperatively.

\section{Discussion}

There are three types of pancreatic fusion anomalies: annular pancreas, pancreas divisum and portal annular pancreas [14]. While portal annular pancreas is the rarest and mostly asymptomatic, annular pancreas (AP), with an incidence ranging from $0.005 \%$ to $0.015 \%$, usually presents as duodenal obstruction in infancy, [15-17]. However, some patients with AP remain asymptomatic
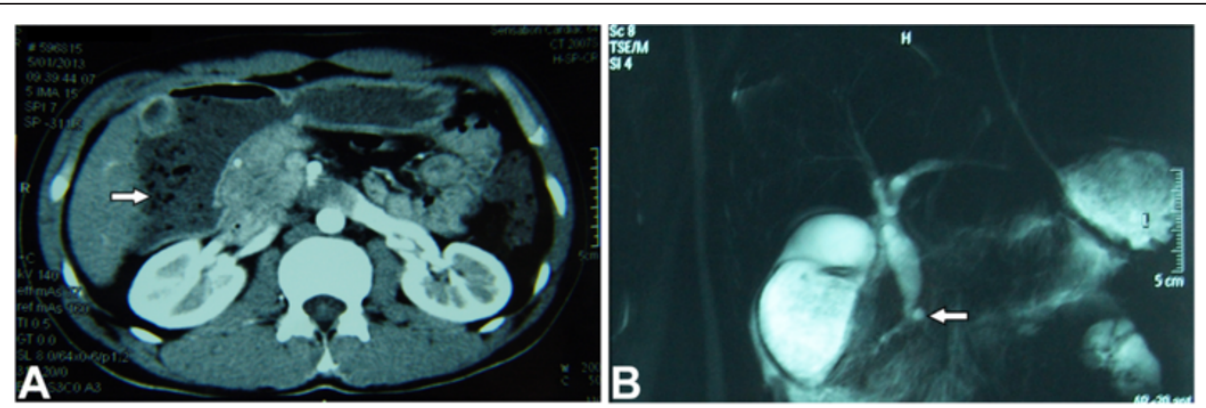

Figure $1 \mathrm{CT}$ image and MRCP appearance. Computerized tomography scan showed the dilated descending part of duodenum (arrow) with stenosis at the distal end of dilated duodenum (A). Magnetic resonance cholangiopancreatography revealed fusiform dilatation of the common bile duct with high confluence of pancreaticobiliary ducts (arrow) with a common channel measured $24 \mathrm{~mm}$ in length (B). 

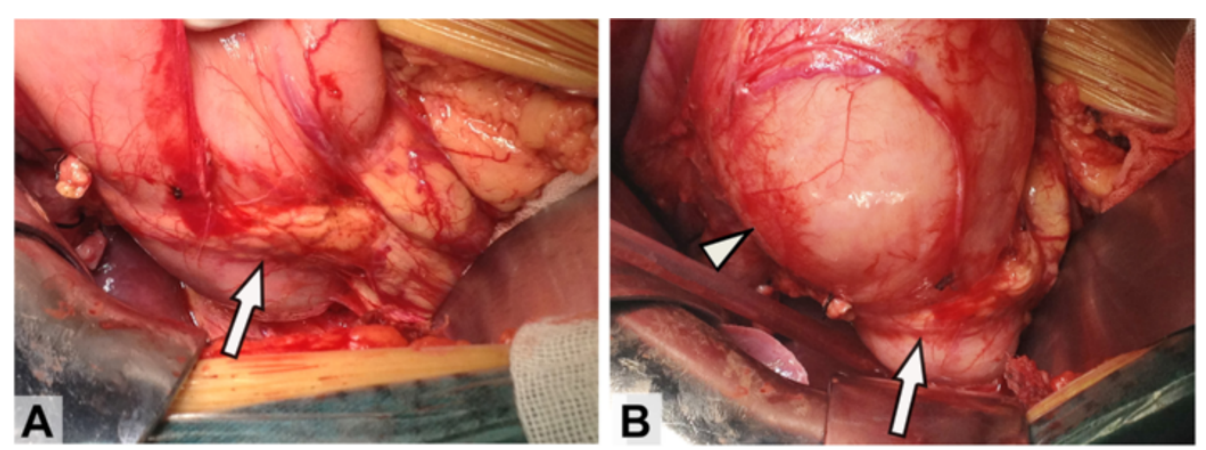

Figure 3 Intraoperative appearance. During laparotomy, a complete ring of pancreatic tissue (arrows) surrounded the descending duodenum (A). Gas charging demonstrated duodenal stenosis with dilatation of the stomach and duodenal bulb (triangle) (B).

until into adulthood, when the disorder manifests as pancreatitis as shown in our patient. From the data on pediatric cases, it was indicated that pancreatitis in the setting of AP may be associated with concomitant pancreaticobiliary malformations including pancreas divisum, PBMJ, or duodenal diverticulum $[18,19]$, which might induce to insufficient drainage of pancreatic secretions and bile. In the present case, biliopancreatic reflux associated with PBMJ was probably the cause of the development of recurrent pancreatitis.

Until now, there were totally 12 cases of concurrent AP with PBMJ, of which the 11 pediatric cases were described previously, Table 1 . Data from these reports showed that most of these patients with AP as well as PBMJ have subjected both duodenoduodenostomy and flow-diversion surgery simultaneously or metachronously. However, prophylactic flow-diversion surgery remains controversial. The recent case reported by Komuro had just received duodenoduodenostomy for AP while prophylactic flow- diversion surgery had not been performed for concomitant PBMJ with bile duct dilatation. According to our experiences, the extremely high levels of pancreatic enzymes in common bile duct or gallbladder should be an important indication for flow-diversion surgery.

PBMJ can be divided into PBMJ with biliary dilatation and PBMJ without biliary dilatation [20]. Out of the 12 reviewed cases, 10 cases (83.3\%) were found with dilated common bile duct. All seven AP associated DA cases showed fusiform dilatation of the common bile duct at 2-12 years of age. However, no choledochal cyst or marked dilation was discovered soon after birth when they underwent initial surgery for the duodenal obstruction. Thus, it should be suggested that although it is often called "congenital" bile duct dilatation, the bile ducts probably undergo a gradual development of dilatation caused by PBMJ after birth.

The diagnosis of PBMJ in patients with AP is often delayed and even missed, not only because of the gradual

Table 1 Reported cases of annular pancreas accompanied with pancreaticobiliary maljunction

\begin{tabular}{|c|c|c|c|c|c|c|c|}
\hline Case & Author & Year & Sex & $\begin{array}{l}\text { Age at duodenal } \\
\text { surgery }\end{array}$ & $\begin{array}{l}\text { Duodenal Lesion } \\
\text { associated with AP }\end{array}$ & $\begin{array}{l}\text { Age at biliary } \\
\text { surgery }\end{array}$ & $\begin{array}{l}\text { Bile duct lesion associated } \\
\text { with PBMJ }\end{array}$ \\
\hline 1 & Komura [5] & 1991 & $\mathrm{~F}$ & 2 years & DS & 2 years & Not dilated \\
\hline 2 & Okada [4] & 1993 & M & 2 days & DA & 12 years & If, $\| f$ \\
\hline 3 & Okada [4] & 1993 & $\mathrm{~F}$ & 7 days & DA & 3years & If, $\| f$ \\
\hline 4 & Nakamura [6] & 1993 & $\mathrm{~F}$ & 3 days & DS & 5 years & If \\
\hline 5 & Komuro [7] & 2000 & M & 11 months & DS & 13 months & Intrapacreatic cyst \\
\hline 6 & Sugimoto [8] & 2002 & $\mathrm{~F}$ & 0 day & DA & 2 years & $\mid f, \| f$ \\
\hline 7 & Oowari [13] & 2003 & $\mathrm{~F}$ & 1 day & DA & 8 years & If \\
\hline 8 & Shih [14] & 2005 & $\mathrm{~F}$ & 3 days & DA & 7 years & If, $\| f$ \\
\hline 9 & Iwai [9] & 2009 & $\mathrm{~F}$ & 1 day & DA & 4 years & If, $\| f$ \\
\hline 10 & Okuyama[12] & 2010 & M & neonatal & DA & 3 years & If \\
\hline 11 & Komuro [11] & 2012 & M & 3 years & DS & NOT & Not dilated \\
\hline 12 & Present case & 2013 & M & 26years & DS & $26 y e a r s$ & If \\
\hline
\end{tabular}

$\mathrm{M}=$ male; $\mathrm{F}=$ Female; $\mathrm{DA}=$ duodenal atresia; $\mathrm{DS}$ duodenal stenosis, If fusiform dilatation of the common bile duct, IIf fusiform dilatation of the intrahepatic bile duct; $\mathrm{NOT}=$ not operated; $\mathrm{PBMJ}=$ pancreaticobiliary maljunction. 
and variable development of bile duct dilatation, but also because of lacking accurate diagnostic maneuver for PBMJ [21]. Thus, although combination of AP and $\mathrm{PBMJ}$ is a rare condition, careful follow-up is required for the patients with AP, taking into account that PBMJ might present clinical symptoms after several years following definitive surgery for AP. Delayed or missed diagnosis of concurrent PBMJ might sometimes cause serious disease or even death. PBMJ is commonly associated with carcinoma of the bile duct and gallbladder $[22,23]$. Meanwhile, bile may also reflux into the pancreatic duct via PBMJ in some conditions, such as with cholangitis or bile stasis in the biliary tract. Refluxed bile may activate pancreatic enzymes, and may thus cause recurrent acute pancreatitis and subsequent chronic pancreatitis, which is related to pancreatic carcinoma [24]. Thus, it is very important for AP patients to receive MRCP and/or ERCP to confirm the coexistence of PBMJ, and long-term careful follow-up make much of senses to the prevention and treatment for the recurrent pancreatitis of such patients.

\section{Conclusions}

AP concurrent with PBMJ usually presents as duodenal obstruction in infancy, while manifests as pancreatitis in adulthood. Although prophylactic flow-diversion surgery remains controversial, careful long-term follow-up is required for patients with AP associated DA or DS considering the association of concurrent PBMJ with various intractable pathologic conditions in the biliary tract and pancreas.

\section{Consent}

Written informed consent was obtained from the patient for publication of this Case report and any accompanying images. A copy of the written consent is available for review by the Editor of this journal.

\section{Abbreviations}

AP: Annular pancreas; PBMJ: Concurrent with pancreaticobiliary maljunction; DA: Duodenal atresia; DS: Duodenal stenosis.

\section{Competing interests}

The authors declare that they have no competing interests.

\section{Authors' contributions}

LC contributed to the design of the study and direction of its implementation. FZT conceived and designed the experiments and supervision of the field activities. LC and TJZ carried out the prepared the Materials of patient and prepared the literature review as well as the Discussion sections of the text. JDR and ZLL conducted the data analysis. All authors read and approved the final version of the manuscript.

\section{Acknowledgements}

We should acknowledge the patient for the written informed consent for publication of this report.

\section{Author details}

'Department of General Surgery, General Hospital of Chengdu Military Command, Chengdu, Sichuan Province, People's Republic of China.

${ }^{2}$ Dujiangyan aviation medical evaluating and training center of PLA Air Force, Chengdu, Sichuan Province, People's Republic of China.

Received: 6 June 2013 Accepted: 15 October 2013

Published: 25 October 2013

\section{References}

1. Etienne D, John A, Menias CO, Ward R, Tubbs RS, Loukas M: Annular pancreas: a review of its molecular embryology, genetic basis and clinical considerations. Ann Anat 2012, 194:422-428.

2. Kamisawa T, Takuma K, Anjiki H, Egawa N, Kurata M, Honda G, Tsuruta K, Sasaki T: Pancreaticobiliary maljunction. Clin Gastroenterol Hepatol 2009, 7:S84-588.

3. Ando H, Kaneko K, Ito F, Seo T, Harada T, Watanabe Y: Embryogenesis of pancreaticobiliary maljunction inferred from development of duodenal atresia. J Hepatobiliary Pancreat Surg 1999, 6:50-54.

4. Okada K, Ohama KTY, Asano S: Two cases of congenital biliary dilatation associated with annular pancreas. J Jpn Soc Pediatr Surg 1993, 4:302-308.

5. Komura J, Yano H, Tanaka Y, Tsuru T: Annular pancreas associated with pancreaticobiliary maljunction in an infant. Eur J Pediatr Surg 1993, 3:244-247.

6. Nakamura TNN, Kusafuka T, Kawata H, Azuma T: Study of pathophysiology on congenital choledochal cyst-embryological consideration on choledochal cyst with annular pancreas. Annual report of 1994 1994, 1994:135-138

7. Komuro H, Makino S, Tahara K: Choledochal cyst associated with duodenal obstruction. J Pediatr Surg 2000, 35:1259-1262.

8. Sugimoto T, Yamagiwa I, Obata K, Ouchi T, Takahashi R, Suzuki R, Shimazaki $Y$ : Choledochal cyst and duodenal atresia: a rare combination. Pediatr Surg Int 2002, 18:281-283.

9. Iwai A, Hamada Y, Takada K, Inagaki N, Nakatake R, Yanai H, Miki H, Araki Y, Sato M, Ono S, Iwai N, Kwon AH: Choledochal cyst associated with duodenal atresia: case report and review of the literature. Pediatr Surg Int 2009, 25:995-998

10. Komuro H, Gotoh C, Urita Y, Fujishiro J, Shinkai T: A pediatric case of an unusual type of annular pancreas presenting with duodenopancreatic reflux. Pediatr Surg Int 2012, 28:715-717.

11. Okuyama H, Kubota A, Kawahara H, Shimizu Y, Watanabe T, Yamanaka H, Tani G, Takeyama Y: Frey procedure for chronic pancreatitis in a child with duodenal atresia and complex pancreaticobiliary disorders. Eur J Pediatr Surg 2010, 20:45-47.

12. Oowari MYT, Kosumi T, Oota Y, Nagahara N: A case of pancreaticobiliary maljunction associated with annular pancreas. Jap J Pediatr Surg 2003, 39:478-480.

13. Shih HS, Ko SF, Chaung JH: Is there an association between duodenal atresia and choledochal cyst? J Pediatr Gastroenterol Nutr 2005, 40:378-381.

14. Tadokoro H, Takase M, Nobukawa B: Development and congenital anomalies of the pancreas. Anat Res Int 2011, 2011:351217.

15. Douie WJ, Krige JE, Bornman PC: Annular pancreas in adults: a report of two cases and a review of the literature. Hepato-gastroenterology 2002, 49:1716-1718.

16. Fu PF, Yu JR, Liu XS, Shen QY, Zheng SS: Symptomatic adult annular pancreas: report of two cases and a review of the literature. Hepatobiliary Pancreat Dis Int 2005, 4:468-471.

17. Maker V, Gerzenshtein J, Lerner T: Annular pancreas in the adult: two case reports and review of more than a century of literature. Am Surg 2003, 69:404-410.

18. Zyromski NJ, Sandoval JA, Pitt HA, Ladd AP, Fogel EL, Mattar WE: Annular pancreas: dramatic differences between children and adults. J Am Coll Surg 2008, 206:1019-1025.

19. Urushihara N, Fukumoto K, Fukuzawa H, Suzuki K, Matsuoka T, Kawashima S, Watanabe K, Hasegawa S: Recurrent pancreatitis caused by pancreatobiliary anomalies in children with annular pancreas. J Pediatr Surg 2010, 45:741-746.

20. Matsumoto Y, Fujii H, Itakura J, Matsuda M, Nobukawa B, Suda K: Recent advances in pancreaticobiliary maljunction. $J$ Hepatobiliary Pancreat Surg 2002, 9:45-54. 
21. Ono S, Fumino S, Iwai N: Diagnosis and treatment of pancreaticobiliary maljunction in children. Surg Today 2011, 41:601-605.

22. Kimura Y, Nishikawa N, Okita K, Furuhata T, Mizuguchi T, Nobuoka T, Nishimori H, Zenbutsu H, Satoh M, Katsuramaki T, Hirata K: Biliary tract malignancy and chronic inflammation from the perspective of pancreaticobiliary maljunction. Oncology 2005, 69:41-45.

23. Deng $Y L$, Cheng NS, Lin YX, Zhou RX, Yang C, Jin YW, Xiong XZ: Relationship between pancreaticobiliary maljunction and gallbladder carcinoma: meta-analysis. Hepatobiliary Pancreat Dis Int 2011, 10:570-580.

24. Kamisawa T, Okamoto A: Biliopancreatic and pancreatobiliary refluxes in cases with and without pancreaticobiliary maljunction: diagnosis and clinical implications. Digestion 2006, 73:228-236.

doi:10.1186/1471-230X-13-153

Cite this article as: Cheng et al: Annular pancreas concurrent with pancreaticobiliary maljunction presented with symptoms until adult age: case report with comparative data on pediatric cases. BMC Gastroenterology 2013 13:153.

\section{Submit your next manuscript to BioMed Central} and take full advantage of:

- Convenient online submission

- Thorough peer review

- No space constraints or color figure charges

- Immediate publication on acceptance

- Inclusion in PubMed, CAS, Scopus and Google Scholar

- Research which is freely available for redistribution 